\title{
GROWTH, SPECTRAL, MECHANICAL AND NONLINEAR OPTICAL CHARACTERIZATION OF POTASSIUM HYDROGEN PHTHALATE CRYSTALS
}

\author{
K. Sivakumar, M. Senthilkumar and C. Ramachandra Raja* \\ Department of Physics, Government Arts College (Autonomous), Kumbakonam- 612002, India. \\ *E-mail: crrajaphy@gmail.com
}

\begin{abstract}
Single crystals of Potassium Hydrogen Phthalate (KHP) have been grown from aqueous solution by slow evaporation technique at $37^{\circ} \mathrm{C}$. The carbon and hydrogen environment in molecular design of KHP is determined by the FT-NMR method. The mechanical strength of KHP was investigated by Vickers microhardness test. The relative SHG efficiency of KHP was measured by employing Kurtz and Perry powder technique using a Q-switched mode-locked Nd:YAG laser emitting $1064 \mathrm{~nm}$. The intensity of the green emission was found to be 1.12 times greater than KDP of KHP crystal. Third-order nonlinear optical properties were determined by the Z-scan procedure by He-Ne laser. Closed aperture Z-scan study reveals the positive nonlinearity in KHP and open aperture Z-scan demonstrates the nonlinear absorption is reverse saturation absorption.

Keywords: Noncentrosymmetry; Reverse indentation size effect; Z- scan measurement; Self-focusing; Reverse saturable absorption.
\end{abstract}

(c) RASĀYAN. All rights reserved

\section{INTRODUCTION}

A nonlinear optical material plays an important role in several applications such as frequency conversion, visual switching and signal refining etc ${ }^{1-3}$. KHP is a semi-organic material used in the X-ray spectroscopy as an analyzer. These KHP crystals are orthorhombic crystal system with space group Pca2 ${ }_{1}$. Electro optic and NLO behaviors of KHP have been studied ${ }^{4-6}$.

In this work, single crystals of KHP have been grown using slow evaporation solution growth method. The grown crystals were characterized by FT-NMR spectroscopy, Vickers micro hardness test, Second harmonic generation (SHG) and third harmonic generation of the Z-scan method and the results are reported.

\section{EXPERIMENTAL}

Single crystals of KHP were grown by slow evaporation method at $37^{\circ} \mathrm{C}$. KHP was dissolved in deionized water and this solution was continuously stirred for 3 hours until it becomes completely transparent. This was filtered by Whatman filter paper and sealed with a perforated top. Then the filtered solution was maintained at $37^{\circ} \mathrm{C}$ using constant temperature bath of accuracy $\pm 0.1^{\circ} \mathrm{C}$. Due to slow evaporation of solvent small crystals of KHP were grown at the bottom of the beaker. After 40 days transparent crystals with the dimensions $20 \times 11 \times 2 \mathrm{~mm}^{3}$ were obtained and are shown in Fig. -1 .

\section{NMR Studies}

\section{RESULTS AND DISCUSSION}

The ${ }^{1} \mathrm{H}$ NMR and ${ }^{13} \mathrm{C}$ NMR spectral analysis are the valuable cogent procedure used to review the design of organic compounds. The ${ }^{1} \mathrm{H}$ NMR (proton) and ${ }^{13} \mathrm{C}$ NMR (carbon) spectra have been recorded for the KHP crystal dissolved in heavy water $\left(\mathrm{D}_{2} \mathrm{O}\right)$ using a Bruker $300 \mathrm{MHz}$ (Ultrashield) ${ }^{\mathrm{TM}}$ instrument at $23{ }^{\circ} \mathrm{C}$ (300 MHz for ${ }^{1} \mathrm{H}$ NMR and $75 \mathrm{MHz}$ for ${ }^{13} \mathrm{C}$ NMR) to confirm the molecular design.

The proton and carbon spectra of KHP crystal are presented in Fig.-2 and Fig.-3 respectively. The chemical shifts are given with assignments in Table-1. 
RASĀYAN J. Chem.

Vol. 11 | No. 2 |676 - 681 | April - June | 2018

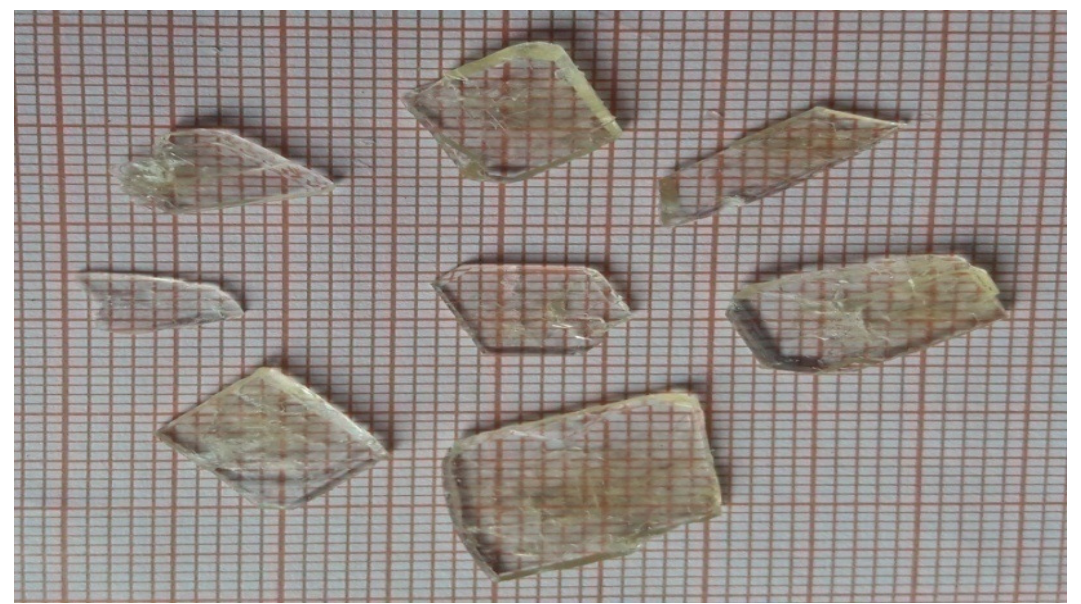

Fig.-1: Photograph of KHP crystals

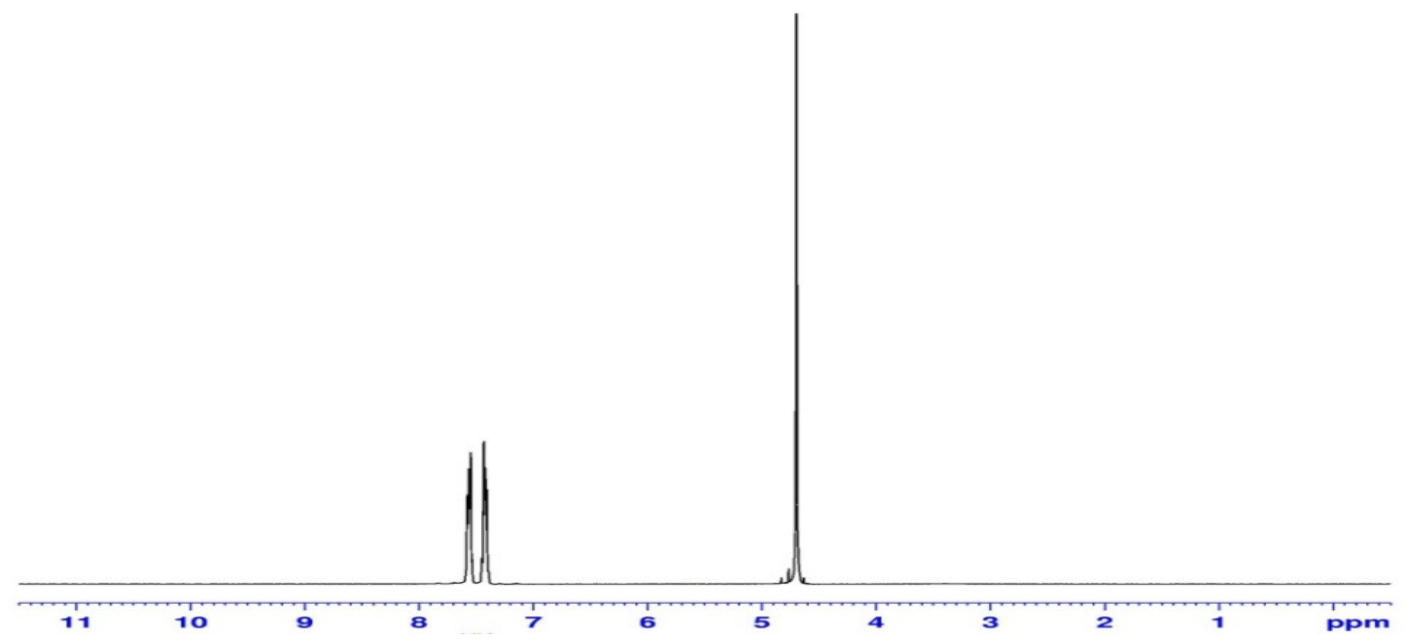

Fig. $-2:{ }^{1} \mathrm{H}$ NMR spectrum of KHP crystal

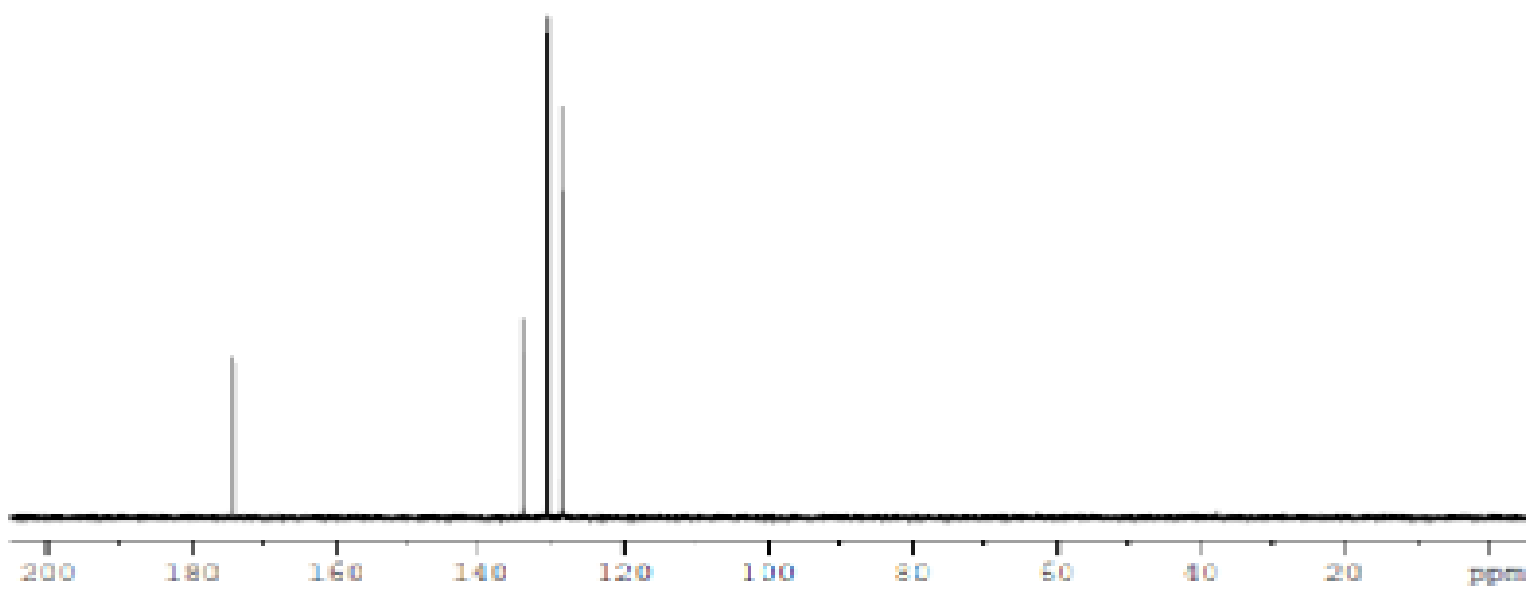

Fig.-3: ${ }^{13} \mathrm{C}$ NMR spectrum of KHP crystal 
In ${ }^{1} \mathrm{H}$ NMR peak due to $\mathrm{C}-\mathrm{H}$ proton of phthalic acid is observed at $7.435 \mathrm{ppm}$ and $\mathrm{COOH}$ proton of phthalic acid is observed at $7.579 \mathrm{ppm}$. The strong intense solvent peak appeared at $4.698 \mathrm{ppm}{ }^{7}$. The ${ }^{13} \mathrm{C}$ NMR spectrum of KHP can be understood with the help of the molecular structure shown in Fig. $-4{ }^{7}$.

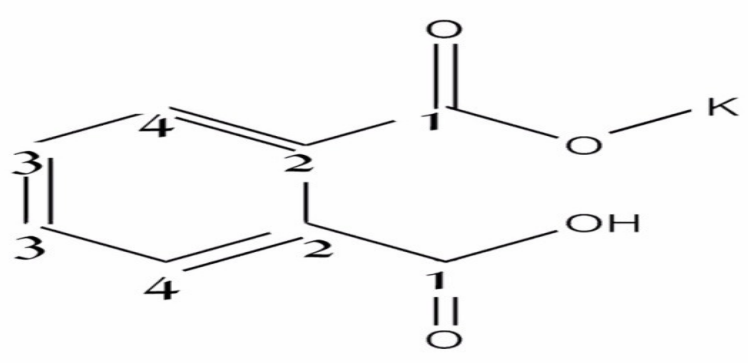

Fig.-4: Carbon atomic Numbering of KHP Crystal

The peak observed at $174.18 \mathrm{ppm}$ corresponds to carbon 1 atom (COOH group of phthalic acid). The peak at $133.86 \mathrm{ppm}$ is due to carbon 2 . The peaks observed at $130.67 \mathrm{ppm}$ and $128.58 \mathrm{ppm}$ are due to carbon 3 and carbon 4 respectively ( $\mathrm{CH}$ group). The results are in agreement with the reported values ${ }^{7}$.

Table-1: Chemical shifts in ${ }^{1} \mathrm{H}$ NMR and ${ }^{13} \mathrm{C}$ NMR spectra of KHP

\begin{tabular}{c|c|l}
\hline Spectra & Chemical shift $(\mathrm{ppm})$ & \multicolumn{1}{c}{ Group identification } \\
\hline${ }^{1} \mathrm{H}$ NMR & 4.698 & $\mathrm{D}_{2} \mathrm{O}$ \\
& 7.435 & CH proton of the Phthalic acid \\
& 7.579 & COOH proton of the Phthalic acid \\
\hline \multirow{2}{*}{${ }^{13} \mathrm{C}$ NMR } & 174.18 & Carbon 1(COOH group) \\
& 133.86 & Carbon 2 \\
& 130.67 & Carbon 3 (CH group) \\
& 128.58 & Carbon 4 (CH group) \\
\hline
\end{tabular}

\section{Micro Hardness Study}

The mechanical strength of crystal was measured by Shimadzu HMV-2t Vickers microhardness tester fitted with the diamond indenter. By shifting the enforced load from $25 \mathrm{~g}$ to $100 \mathrm{~g}$ the crosswise diameter was measured. Vickers Hardness number $\mathrm{H}_{\mathrm{v}}$ was determined by the relation:

$$
\mathrm{H}_{\mathrm{v}}=1.8544 \mathrm{P} / \mathrm{d}^{2}\left(\mathrm{Kg} / \mathrm{mm}^{2}\right)
$$

Where, $\mathrm{P}$ is load and $\mathrm{d}$ is mean crosswise diameter. The plot of hardness number with load is shown in Figure 5. It is clear that hardness number is increasing with applied load. The increase in $\mathrm{H}_{\mathrm{v}}$ with increasing load is due to the reverse indentation size effect (RISE) ${ }^{8}$.

\section{Second Harmonic Generation Analysis}

The Kurtz and Perry method was utilized to measure powder SHG efficiency of KHP crystals. KHP crystals were grand into very fine powder and packed in a micro capillary tube which served as the sample cell. Then it was kept in the path of Nd:YAG laser. The generation of green light confirmed the NLO property of KHP. The NLO efficiency of reference material KDP is $55 \mathrm{mV}$ while that of KHP is $62 \mathrm{mV}$. The SHG efficiency of KHP single crystals is 1.12 times greater than the KDP crystal ${ }^{9}$.

\section{Z-scan Measurement}

The third-order nonlinear optical property of KHP single crystal was analyzed by Z-scan technique. The nonlinear refractive index $\left(\mathrm{n}_{2}\right)$, the nonlinear absorption coefficient $(\beta)$ of KHP single crystal was evaluated 
by Z-scan technique. In this method, He-Ne laser $(632.8 \mathrm{~nm})$ with beam radius $2 \mathrm{~mm}$ was used to scan the sample. $\mathrm{n}_{2}$ was calculated by the relation,

$$
\mathrm{n}_{2}=\frac{\Delta \varphi}{\mathrm{KI}_{0} \mathrm{~L}_{\text {eff }}}
$$

Where $K=2 \pi / \lambda, I_{0}$ is the intensity of the laser beam at the focus $(Z=0), L_{\text {eff }}$ is the effective thickness of KHP which was estimated by the formula,

$$
\mathrm{L}_{\text {eff }}=\frac{1-\exp (-\alpha \mathrm{L})}{\alpha}
$$

Here $\alpha$-represents linear absorption coefficient and L is the thickness of sample $(2 \mathrm{~mm})$. Closed aperture Zscan curve was shown in Fig.-6. In a closed curve, valley followed by peak reveals the positive nonlinear refractive index $\left(\mathrm{n}_{2}\right)$ of material. This suggests that crystal having self-focusing nature.

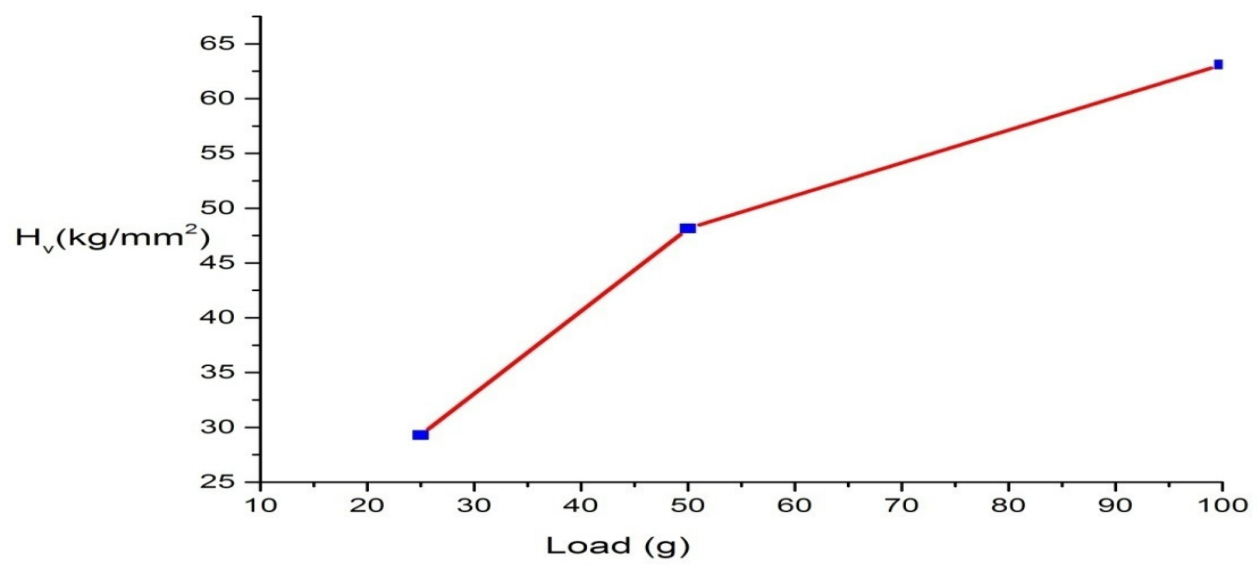

Fig. -5: Variation of $\mathrm{H}_{\mathrm{v}}$ for various loads

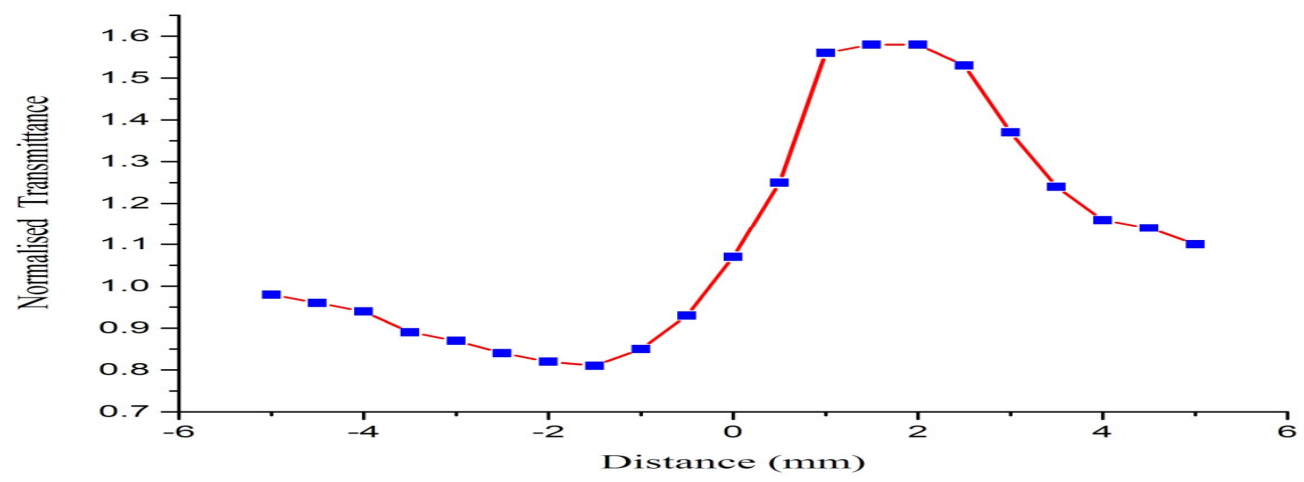

Fig. -6: Closed aperture Z-scan pattern of KHP crystal

From the open aperture Z-scan data, $\beta$ is determined using the expression,

$$
\beta=\frac{2 \sqrt{2} \Delta T}{I_{0} \text { Leff }}
$$

Where $\Delta T=1-T_{v}$. $\left(T_{v}-\right.$ valley value at the open aperture Z-scan curve) Fig.-7. Represents the open aperture Z-scan curve. In the figure, minimum transmission occurs near the focus. This is due to reverse saturable absorption of the material ${ }^{10}$. 


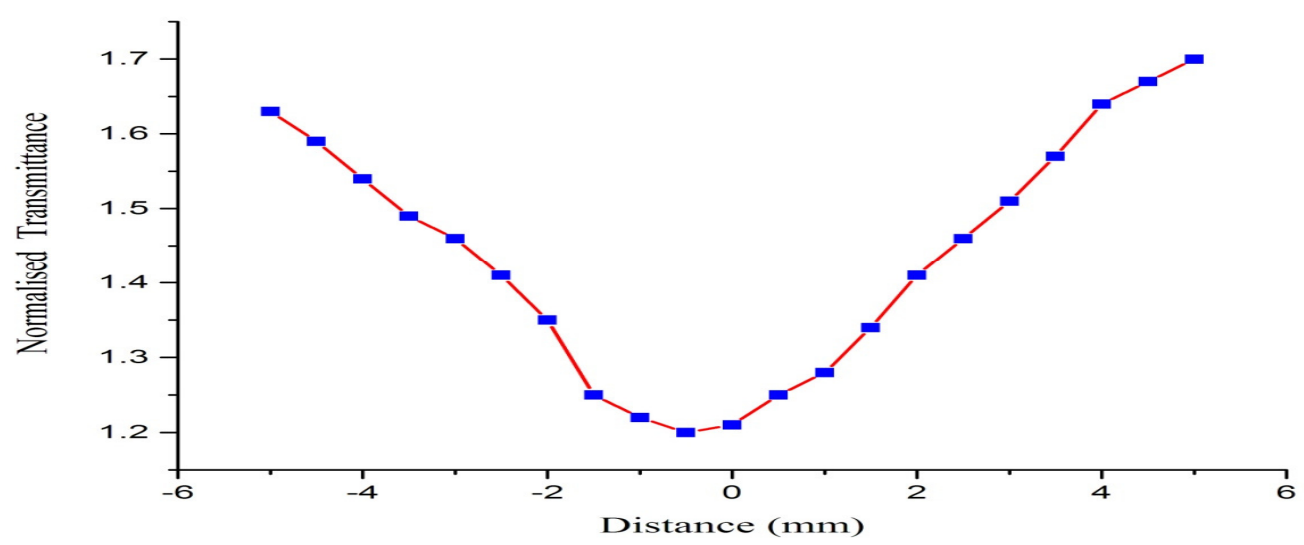

Fig.-7: Open aperture Z-scan pattern of KHP crystal

The real and imaginary parts of $\chi^{(3)}$ are defined as:

$$
\begin{aligned}
& \operatorname{Re} \chi^{(3)} \mathrm{esu}=10^{-4} \quad \varepsilon_{0} C^{2} \mathrm{n}_{0}^{2} \mathrm{n}_{2} / \pi \quad\left(\mathrm{cm}^{2} / \mathrm{W}\right), \\
& \operatorname{Im} \chi^{(3)} \mathrm{esu}=10^{-2} \varepsilon_{0} C^{2} \mathrm{n}_{0}^{2} \lambda \beta / 4 \pi^{2} \quad(\mathrm{~cm} / \mathrm{W}),
\end{aligned}
$$

Where $\varepsilon_{0}$ is the vacuum permittivity, $\mathrm{n}_{0}$ is the linear refractive index of the sample and $\mathrm{C}$ is the velocity of light in vacuum. The absolute value of $\chi(3)$ is calculated from:

$$
\chi^{3}=\sqrt{\left[\operatorname{Re}\left(\chi^{3}\right)\right]^{2}+\left[\operatorname{Im}\left(\chi^{3}\right)\right]^{2}}
$$

The nonlinear parameters such as $\mathrm{n}_{2,}, \beta$, and $\chi^{3}$ have been evaluated and tabulated in Table- 2 .

Table-2: Measurement details and the results of the Z-scan technique

\begin{tabular}{c|c}
\hline Laser beam wavelength $(\lambda)$ & $632.8 \mathrm{~nm}$ \\
\hline Lens focal length $(\mathrm{f})$ & $18.5 \mathrm{~cm}$ \\
\hline Optical path distance $(\mathrm{Z})$ & $115 \mathrm{~cm}$ \\
\hline Spot-size diameter in front of the aperture $\left(\omega_{\mathrm{a}}\right)$ & $1 \mathrm{~cm}$ \\
\hline Aperture radius $\left(\mathrm{r}_{\mathrm{a}}\right)$ & $2 \mathrm{~mm}$ \\
\hline Incident intensity at the focus $(\mathrm{Z}=0)$ & $3.13 \mathrm{MW} / \mathrm{Cm}^{2}$ \\
\hline Nonlinear refractive index $\left(\mathrm{n}_{2}\right)$ & $3.156 \times 10^{-12} \mathrm{~cm}^{2} / \mathrm{W}$ \\
\hline Nonlinear absorption coefficient $(\beta)$ & $-6.7 \times 10^{-4} \mathrm{~cm} / \mathrm{W}$ \\
\hline The real part of the third-order susceptibility $[\operatorname{Re}(\chi 3)]$ & $1.53 \times 10^{-10} \mathrm{esu}$ \\
\hline Imaginary part of the third-order susceptibility $\left[\operatorname{Im}\left(\chi^{3}\right)\right]$ & $7.71 \times 10^{-6} \mathrm{esu}$ \\
\hline Third-order nonlinear optical susceptibility $(\chi 3)$ & $7.86 \times 10^{-4} \mathrm{esu}$ \\
\hline
\end{tabular}

\section{CONCLUSION}

The single crystals of KHP were been successfully grown from low-temperature solution growth technique. The molecular structure KHP crystal was established by ${ }^{1} \mathrm{H}$ and ${ }^{13} \mathrm{C}$ NMR techniques. From the micro hardness measurement, it was informed that the hardness increased with the increase of load until saturation occurred. The SHG efficiency of KHP crystals was confirmed by green colour emission. $\mathrm{n}_{2,}, \beta$, and $\chi^{3}$ are calculated using Z-scan analysis.

\section{ACKNOWLEDGMENT}

Author C.R acknowledges Council of Scientific and Industrial Research (CSIR), New Delhi for financial aid (scheme no: 03(1301)/13/EMR II). The authors are very grateful to Dr. P.K. Das, Indian Institute of 
RASĀYAN J. Chem.

Vol. 11 | No. 2 |676 - 681 | April - June | 2018

Science, Bangalore (IISc) for measurement of SHG efficiency, National Institute of technology (NIT), Trichy for Z-scan studies, Sastra University, Thanjavur for FT- NMR studies and St. Joseph's College, Trichy for Vicker'sMicro hardness studies.

\section{REFERENCES}

1. P. Punitha, S. Senthilkumar, S. Parthiban, Int. J. Chem. Tech. Res., 7, 3171 (2014-2015)

2. V. Chithambaram, S. Jerome Das, R. Arivudai Nambi, K. Srinivasan, S. Krishnan, J. Physica B, 405, 2605(2010), DOI: 10.1016/j.physb.2010.03.004

3. D. R. Kanis , M.A. Ratner, T.S.J. Marks, Chem. Rev., 94, 195(1994), DOI: 10.1021/cr00025a007

4. J.George, S.K.J. Premachandran, Phys. D, 14, 1277(1981), DOI: 10.1088/0022-3727/14/7/015

5. G. Babu Rao, P. Rajesh , P. Ramasamy, J. Appl. Phys., A-Matter, 122, 175 (2016), DOI: 10.1007/s00339-016-9693-7

6. A. Miniewicz, J.Mol. cryst. Liq. Cryst., 229, 13(1993), DOI: 10.1080/10587259308032169

7. Spectral database for organic compounds (SDBS), http://sdbs.db.aist.go.jp/sdbs/cgibin/direct_frame_top.cgi

8. P. K. Sivakumar, J. Saravana Kumar, R. Mohan Kumar, R. Kanagadurai , S. Sagadevan , J. Mat. Res., 19, 4 (2016), DOI: 10.1590/1980-5373-MR-2016-0055

9. S.R. Thilagavathy, P. Rajesh, P. Ramasamy, K. Ambujam , J. Spectrochim. Acta A, 127, 248(2014), DOI: 10.1016/j.saa.2014.01.137

10. T.C. Sabari Girisun, S. Dhanuskodi, J. Cryst. Res. Technol, 44, 1297(2009), DOI: $10.1002 /$ crat.200900351

[RJC-1896/2017] 